\title{
Radiographic assessment of pleuropulmonary disease in asbestos workers: posteroanterior, four view films, and computed tomograms of the thorax
}

\author{
R BÉGIN, M BOCTOR, D BERGERON, A CANTIN, Y BERTHIAUME, S PÉLOQUIN, \\ G BISSON, AND G LAMOUREUX \\ From the Groupe de Recherche Pulmonaire, Centre Hospitalier Universitaire de Sherbrooke, Universite de \\ Sherbrooke, Sherbrooke, Quebec, Canada, J1H 5 N4
}

\begin{abstract}
To study the clinical usefulness of computed tomography (CT) scanning of the thorax in asbestos related pleuropulmonary disease, 127 long term asbestos workers of the mines and mills in the Eastern Townships of Québec were examined. The CT scan was compared with the standard posteroanterior (PA) chest film and the four view films using the ILO grading system for profusion of disease. Six lung areas and six pleural sites were studied. On the basis of the usual diagnostic criteria, $41 \%$ of the workers had asbestosis. For profusion of parenchymal disease, there was an excellent correlation $(r=0.96, p<0.001)$ between PA and four view films and the latter did not significantly increase the total profusion score; the CT scan correlated less well with the PA film $(r=0.79, \mathrm{p}<0.01)$ and the scatter of the data was larger. In 10 of the $53(19 \%)$ workers with asbestosis the pulmonary lesions were not recognised by CT scan. For profusion of pleural plaques, there was an excellent correlation $(p=0.91, p<0.001)$ between PA and four view films; scores were identical in $73 \%$, higher for PA in $7 \%$, and higher for four view films in $19 \%$. CT scan scores, however, were identical with PA films in $31 \%$, higher for CT scan in $13 \%$ (owing to higher scores on lateral pleural sites), and lower for CT scan in 56\% (owing to lower scores at diaphragm and costophrenic angle sites). Pleural calcifications were identified in 24 workers for a total of 40 sites; 13 as possible, $31 \%$ identified by two modes, and 27 as definite. Of the latter, 14 were seen only on CT scan. In the workers with rigid pressure volume curve of the lung and increased Gallium-67 lung uptake only, CT scan total scores were not significantly higher than in those without these markers of early interstitial lung disease $(5 \pm 1 v 4 \pm 1, \mathrm{p}<$ 0.05 ). Thus the four view films and CT scan appear to be useful mainly in the assessment of pleural disease. The four view film identifies more sites of pleural plaques and the CT scan more pleural calcified plaques.
\end{abstract}

In the clinical investigation of pleuropulmonary disease computed tomography of the thorax (CT scan) often yields information not available by other methods. ${ }^{1-4}$ It has been established as a valuable tool for the study of mediastinal, chest wall, and pleural conditions and also pulmonary parenchymal abnormalities such as the solitary nodule and pulmonary metastases.

In asbestos related pleuropulmonary diseases, earlier clinical studies ${ }^{56}$ on relatively small popula-

Received 20 June 1983

Accepted 22 August 1983 tions of patients have found that the CT scan was significantly more sensitive than conventional chest $x$ rays in the detection of disease, but its routine use in the evaluation of asbestos workers is still open to question.

To study the usefulness of the CT scan in the setting of a workman compensation board examination, we obtained a CT scan of the thorax in 127 long term asbestos workers who were concomittantly evaluated for pleuropulmonary disease by conventional posteroanterior (PA), lateral and oblique (4 view) $x$ rays, and clinical and functional evaluations. 


\section{Materials and methods}

\section{PATIENTS}

The average age of the 127 workers in the study was $58 \pm 3$ (SE) years (range 40-72) and they had been exposed to Canadian chrysotile asbestos only in the mines and mills of the Eastern Townships of Quebec for an average $29 \pm 3$ years (range 7-45); they had no history of pulmonary disease. On the basis of job record and occupational history, these workers had, on average, been heavily exposed to asbestos dust during the first 10 years of employment, moderately exposed during the following 10 years, and had lower exposure during their most recent years of employment as their employers have been complying with the 2 fibres per cc of air threshold limit value regulation in Quebec. Ninety per cent were either current or ex-cigarette smokers and had smoked, on average $29 \pm 3$ pack-years.

\section{CLINICAL EVALUATION}

All patients had a history and complete physical examination with emphasis on the detection of abnormalities suggestive of asbestosis. ${ }^{7}$ More specifically, a questionnaire directed at eliciting respiratory symptoms and factors associated with chronic obstructive pulmonary disease, lifetime smoking habits, and occupational history was administered. ${ }^{8}$ From the companies' work records, we were able to calculate exposure time for each job and to estimate asbestos dust on a scale of 0 to 3 in the different working areas. An asbestos dust exposure index derived from the exposure time and estimate of dust exposure was computed for each worker. The presence of inspiratory rales was graded as follows: grade $0=$ no rales; grade $0 \cdot 5=$ unilateral end inspiratory rales unchanged by coughing and deep breathing; grade 1 = fine end inspiratory rales at both lung bases unchanged by the above manoeuvres; grade $2=$ mid and end inspiratory rales unchanged by the above manoeuvres; grade 3 $=$ abundant rales during more than half of inspiratory capacity and unchanged by the above manoeuvres. ${ }^{9}$

\section{CHEST $X$ RAY}

Standard high kilovoltage posteroanterior, lateral, and oblique films were obtained at maximal inspiration. The lung parenchyma was graded for profusion of small opacities by three observers according to the ILO classification. ${ }^{10}$ The profusion of irregular opacities was scored on a linear scale of 0 to 10 ; grade $0 /$ and $0 / 0=0 ; 0 / 1=1 ; 1 / 0=2 ; 1 / 1=3 ; 1 / 2$ $=4 ; 2 / 1=5 ; 2 / 2=6 ; 2 / 3=7 ; 3 / 2=8 ; 3 / 3=9 ; 3 / 4$ $=10$. The category of profusion is based on the viewer's assessment of the concentration of opacities by comparison with the standard radiographs provided by the ILO. This classification recognises the existence of a continuity of change from no small opacities $(0 /-$ or $0 / 0)$ to the most advanced category (3/4). The profusion of opacities was recorded separately for the six lung fields. Pleural changes were also graded in terms of site, width, and extent of pleural thickening according to the ILO classification. For each of the six sites of pleural thickening (chest walls, diaphragms, and costophrenic angles) the width category $\mathrm{a}, \mathrm{b}$, or $\mathrm{c}$ was converted numerically to 1,2 , or 3 and multiplied by the extent score 1,2 , or 3 . Pleural calcifications were also recorded in terms of site and extent according to the ILO classification. A total score of pleuropulmonary changes was computed for each worker by summing the scores of each lung field and each pleural thickening and pleural calcification site.

\section{COMPUTED TOMOGRAMS OF THE THORAX}

All CT examinations were performed on a General Electric Model 8800 scanner (Canadian General Electric Co, Montréal, Quebec). Ten tomograms of $1 \mathrm{~cm}$ thickness were obtained on each patient, with wide, and 10 with narrow, windows for adequate assessment of pulmonary, chest wall, and pleural changes. In the upper lung fields these were $3 \mathrm{~cm}$ apart and in the lower lung field $2 \mathrm{~cm}$ apart. The lowest tomograms were obtained through the diaphragms. All were obtained without contrast media, half in the supine and half in the prone position during a 9.4 second breathholding procedure at near functional residual capacity. The profusion of pleuropulmonary disease as evaluated by the CT scan technique was graded using the same basic principles as the ILO system for grading pleuropulmonary disease in the chest $x$ ray. Pleural abnormalities were scored at six sites (chest walls, costophrenic angles, and diaphragms) in terms of site, width, and extent; profusion of parenchymal disease was scored at six sites (upper, middle, and lower lung fields) on a 0-10 scale derived from the ILO classification. Total scores of pleuropulmonary changes were computed for each worker.

\section{PULMONARY FUNCTION}

The lung volumes, pressure-volume curves, flowvolume curves, and diffusion capacities $\left(\mathrm{DL}_{\mathrm{CO}}\right)$ were measured by the standard methods" in our laboratory. ${ }^{9}$ Functional residual capacity (FRC) was determined by the helium rebreathing method and after initial equilibration at least three vital capacities were obtained to measure all lung volumes. The static expiratory lung compliance was obtained by monitoring transpulmonary pressure using a $7 \mathrm{ml}$ balloon catheter and an airway catheter 
sampling pressure at the mouth connected to a Hewlett-Packard 270 differential transducer (Hewlett-Packard, Walham, MA) and by monitoring gas flow at the airway opening with a Fleisch No 2 pneumotachograph attached to a flow meter integrator recorder system. For each subject, after a standard volume history was obtained, the maximal oesophageal pressure $\left(\mathrm{P}_{\text {oes }} \max \right)$ at total lung capacity was obtained in triplicate with the airway opened during the third. second of breathholding. Thereafter, inspiratory capacities were repeated to obtain some 20 points on the expiratory phase of the manoeuvre, again during the third second of breathholding. A best fit curve was drawn from all points and used for each subject. For the measurement of maximal expiratory flow rates $\left(\dot{\mathrm{V}}_{\max }\right)$, we used the Floop flow-volume curve apparatus (Med Science, St-Louis MO). The predicted values used in this study were those of Bates and coworkers ${ }^{11}$ for lung volumes, flow rates, and $\mathrm{DL}_{\mathrm{CO}}$ and of Bégin and associates $^{12}$ for pressure volume curves.

\section{GALLIUM-67 LUNG UPTAKE}

Two $\mathrm{mCi}$ of $\mathrm{Ga}-67$ citrate (New England Nuclear Corp, Billerica, MA) were injected intravenously into each patient. Forty eight hours later, anterior, posterior, and lateral scans from neck to pelvis were recorded with a Dyna 4c/15-61 camera (Picker,
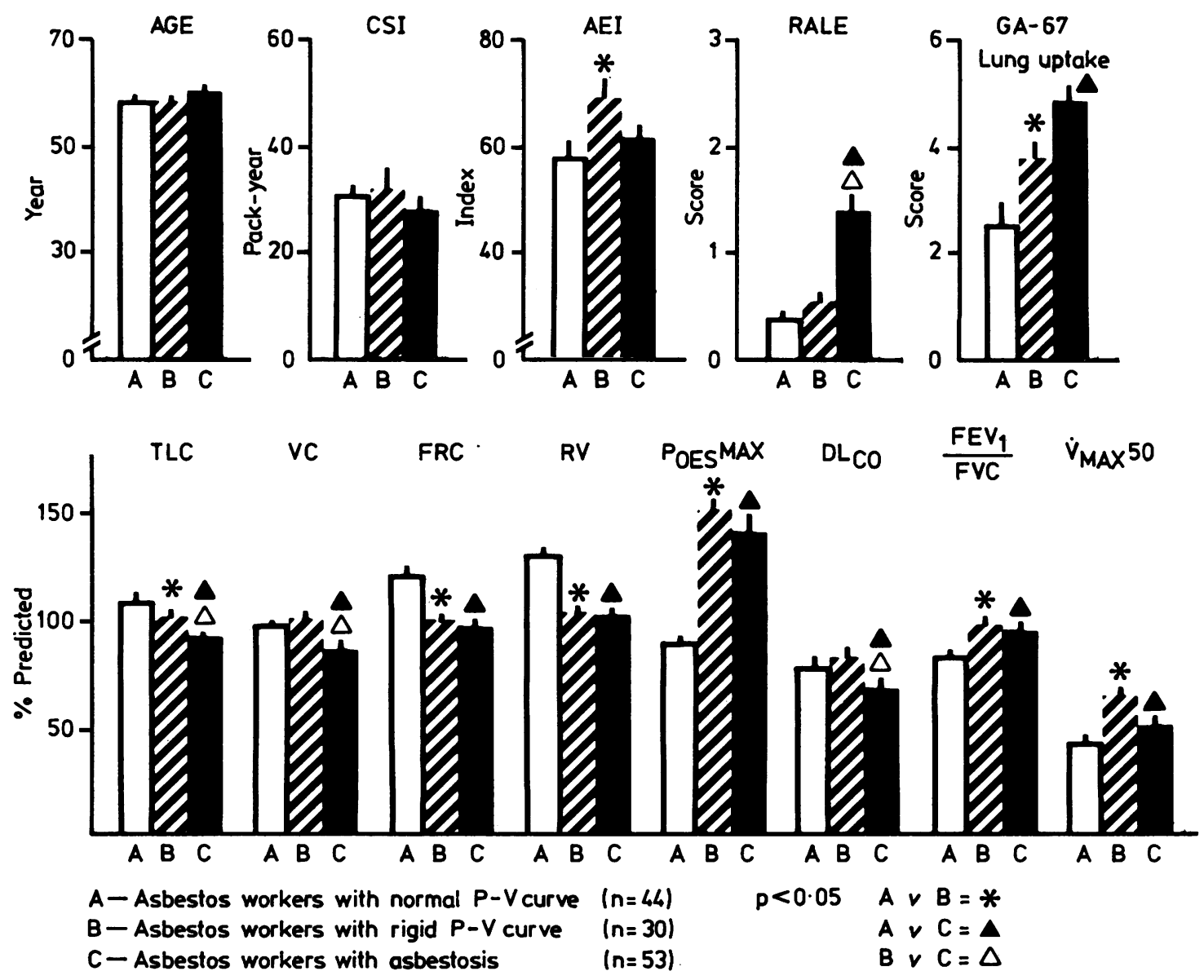

Fig 1 Clinical and functional data of each subset of workers (mean \pm 1 SE). CSI = Cigarette smoking index; AE1 = Asbestos exposure index; $T L C=$ Total lung capacity; $V C=$ Vital capacity; $F R C=$ Functional residual capacity; $R V=$ Residual volume; $P_{\text {oes }} \max =$ Maximal oesophageal pressure at total lung capacity; $D L_{C O}=$ Diffusion capacity for carbon monoxide (transfer factor); $F E V, F V C=$ Forced expired volume in one second over forced vital capacity; $\dot{V}_{\text {max }} 50=$ Maximal expiratory flow rate at $50 \%$ FVC. Predicted values are taken from Bates and associates ${ }^{1}$ except for $P_{\text {oes }}$ max predictions (from Bégin et $\mathbf{a l}^{12}$ ). 
Northford, CT) coupled with a Cromenco system 3 microprocessor (Cromenco, Mountainview, CA). The software for the acquisition and processing of the data was developed in our institution. Grading of the Ga-67 pulmonary uptake was done blind. Each lung field on the posterior scan was divided into three areas. The average intensity of Ga-67 uptake in each area was graded by the computer on a 17 point scale: grade 0 was equal to the average body background uptake as measured under both kidneys. Grade 16 represented the maximal liver uptake, and the in-between grades were equally distributed. Because the Ga-67 lung uptakes are relatively uniform in the six lung fields in normal subjects and in patients with asbestosis, the scores of each of the six lung areas were averaged to yield an index of pulmonary Ga-67 uptake between 0 and 16. Details of the method and its value in the study of interstitial lung diseases have been reported elsewhere. ${ }^{9}{ }^{13}$
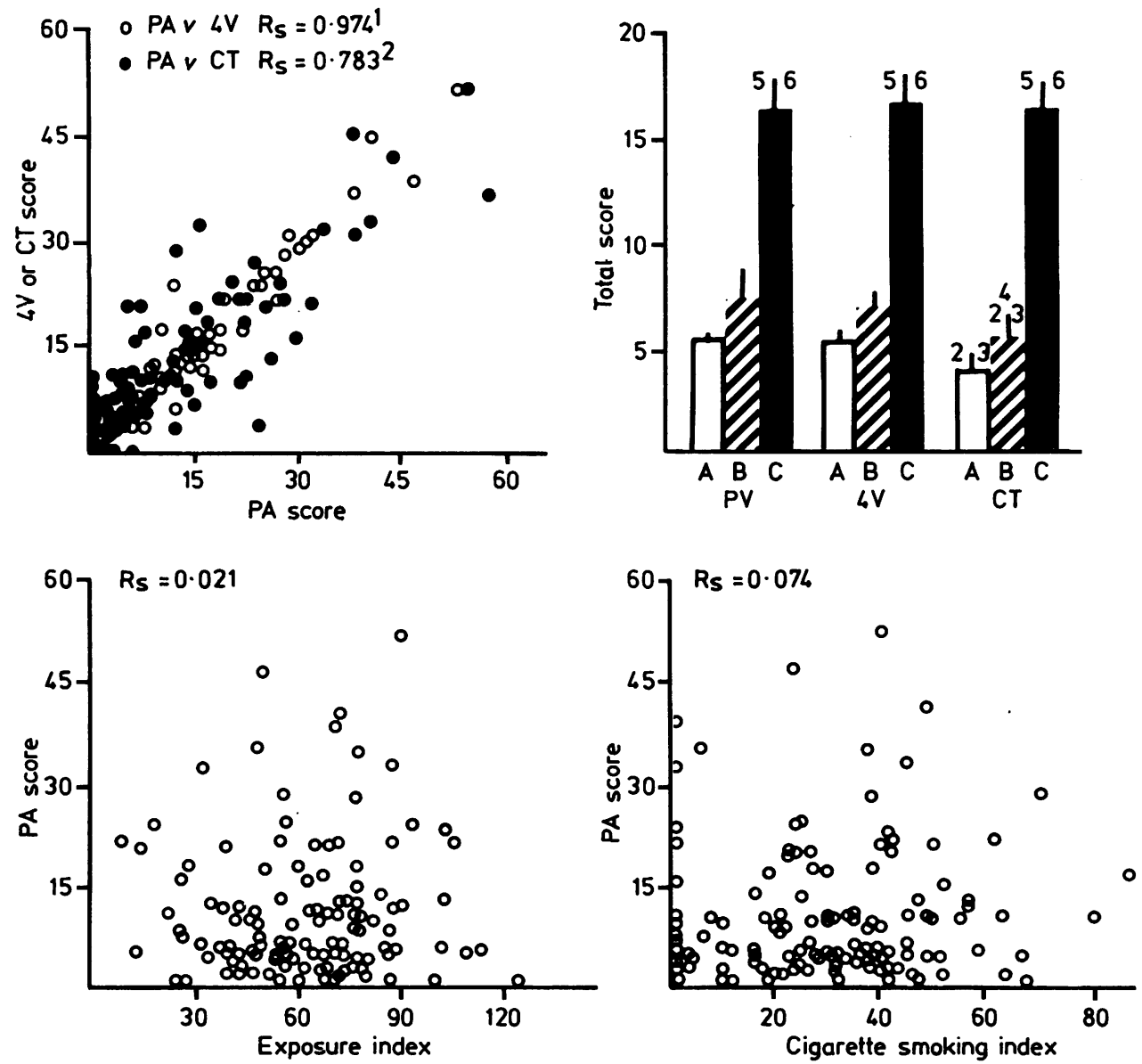

A-Asbestos workers with normal lung $P-V$ curve
$B$ - Asbestos workers with rigid lung $P-V$ curve

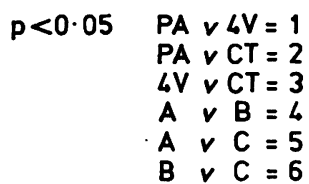

Fig 2 Total scores of pleuropulmonary disease assessed by each of the three radiological methods. $P A=$ posteroanterior chest film; $4 \mathrm{~V}=$ Four view $(P A+$ obliques + lateral $)$ chest films; $C T=$ Computed 
DIAGNOSIS OF ASBESTOSIS

Asbestosis was diagnosed using the criteria recommended by the Canadian Task Force on occupational respiratory disease ${ }^{14}$ :

\section{Essential criteria}

History of significant exposure to asbestos dust, and

Small irregular opacities on chest $x$ ray film, category 1 according to the ILO/UC 1971 international classification (grade $1 / 10$ and above in the 1980 classification).

\section{Confirmatory criteria}

Evidence of a restrictive pattern of pulmonary function,

Progressive shortness of breath on exertion, Inspiratory crackling rales at both lung bases, and Clubbing of fingers or toes or both.

\section{Pathological criterion}

Evidence of interstitial fibrosis with a sufficient number of fibres or ferruginous bodies.

The diagnosis of asbestosis was established when at least the two essential criteria and two of the confirmatory criteria or the pathological criterion were present. The criteria for a restrictive pattern of lung function were reduction in total lung capacity, vital capacity, and diffusing capacity associated with a rightward displacement of the lung $\mathrm{P}-\mathrm{V}$ curve and falling arterial $\mathrm{PO}_{2}$ during exercise as suggested by Bates et al. "The Ga 67 lung uptake was not used to make the diagnosis, although we have recently documented its use in the early diagnosis of the disease..$^{913}$

\section{SUBSETS OF ASBESTOS WORKERS BASED ON DIAGNOSTIC CRITERIA}

For the purpose of defining the presence and nature of the disease in our workers, we divided the population into three subsets: group A was composed of 44 workers who did not meet the diagnostic criteria for asbestosis, did not have a rigid lung P-V curve, and had a normal Ga 67 lung scan; the 30 workers in group B also did not meet the diagnostic criteria for asbestosis but had a rigid lung $\mathrm{P}-\mathrm{V}$ curve or an increased lung uptake of Ga 67 (26/30 had both), or both; the other 53 patients in group $\mathrm{C}$ met the diagnostic criteria for the disease, the P-V curve was rigid in all, and in 45 the Ga-67 lung uptake increased.

\section{STATISTICAL ANALYSIS}

All results are expressed as the mean \pm SEM. The data were tested by the Student $t$ test or the Mann-Whitney $U$ test for differences between groups, by the Wilcoxon matched pairs signed rank test for differences between radiological methods, and by Spearman's correlation procedure when appropriate. ${ }^{1516}$

\section{Results}

\section{CLINICAL AND FUNCTIONAL DATA}

Figure 1 shows the non-radiological data of the population divided into three subsets based on diagnostic criteria. The three subsets did not differ in terms of age and cigarette smoking index, but the workers in group B had a significantly higher asbestos exposure index $(\mathrm{AE} 1(\mathrm{p}<0.05)$. The profusion of rales was scored significantly higher only in the workers with established asbestosis (group C) but but the $\mathrm{Ga} 67$ lung uptake was significantly higher in groups $B$ and $C$ than in group $A$. In the latter group Ga 67 lung uptake did not differ from a group of control subjects with similar smoking habits. ${ }^{13}$ From the pulmonary function data it was seen that group A had a mild obstructive pattern with a greater than predicted functional residual capacity (FRC) (119 \pm $4 \%)$ and residual volume (RV) $(133 \pm 7 \%)$ and a lower than predicted forced expired volume in one second/forced vital capacity (FEV/FVC) $(82 \pm 3 \%)$ and maximal expiratory flow rate at $50 \%$ FVC $\left(\dot{\mathrm{V}}_{\max } 50\right)(43 \pm 5 \%)$; this was not unexpected in a group of older men, $90 \%$ of whom were current or ex-cigarette smokers. Group B (also largely composed of smokers) did not have an obstructive pattern of lung function but had significantly higher maximal oesophageal pressure $\left(\mathrm{P}_{\text {oesmax }}\right)(151 \pm$ $5 \%$ ). The workers with asbestosis (Group C) had a restrictive pattern of lung function with reduced total lung capacity (TLC) $(93 \pm 2 \%)$, vital capacity $(88 \pm 2 \%)$, diffusion capacity $\left(\mathrm{DL}_{\mathrm{CO}}\right)(90 \pm 3 \%)$, increased $\mathrm{P}_{\text {oes }} \max (140 \pm 8 \%)$, and $\mathrm{FEV} / \mathrm{FVC}(95$ $\pm 2 \%$ ).

\section{TOTAL PLEUROPULMONARY DISEASE}

Figure 2 shows the analysis of the total profusion score of pleuropulmonary disease as assessed by the three radiological studies. The three methods yielded comparable results except for a larger dispersion of the CT scan data, which did not correlate as strongly with the PA score as did the four view scores $(\mathrm{p}=0.78$ for PA $v$ CT and $\mathrm{p}=\mathbf{0 . 9 7}$ for PA $v$ $4 \mathrm{~V})$. Furthermore, there was no significant relationship between the indices of total profusion of disease by either method and the asbestos exposure index $(r$ $=0.02)$ or the cigarette smoking index $(r=0.07)$. The group B scores did not differ significantly between methods. 
- PA $v$ LV Rs $=0.964^{1}$

- $P A \vee C T R_{s}=0.788^{2}$
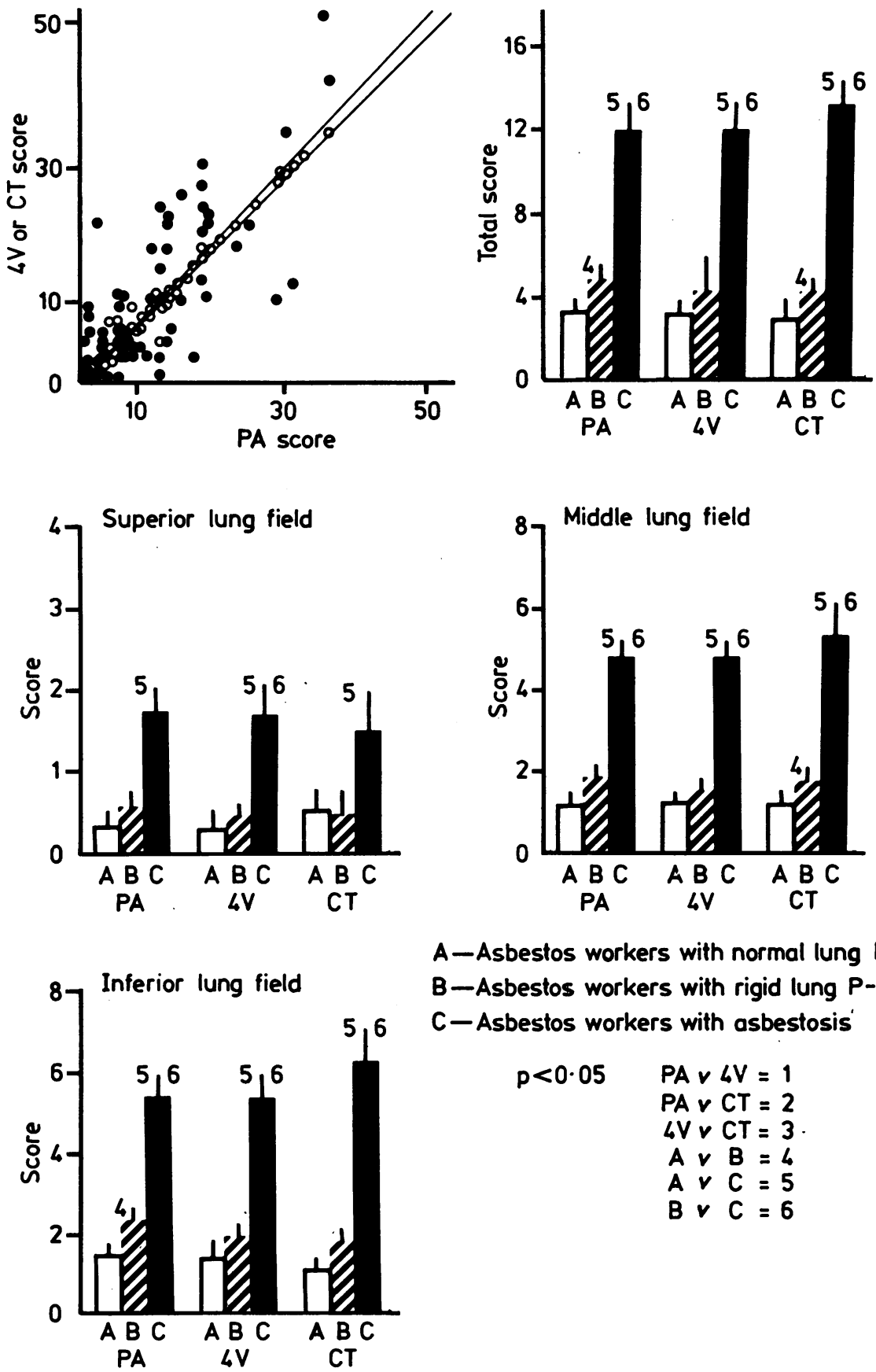

A-Asbestos workers with normal lung $P-V$ curve

$B$-Asbestos workers with rigid lung P-V curve

C-Asbestos workers with asbestosis'

$$
\begin{array}{r}
P<0.05 \quad P A \vee L V=1 \\
P A \vee C T=2 \\
L V \vee C T=3 \\
A \vee B=4 \\
A \vee C=5 \\
B \vee C=6
\end{array}
$$

Fig 3 Total and regional scores of profusion of opacities by the three methods. Abbreviations as in fig 2. 

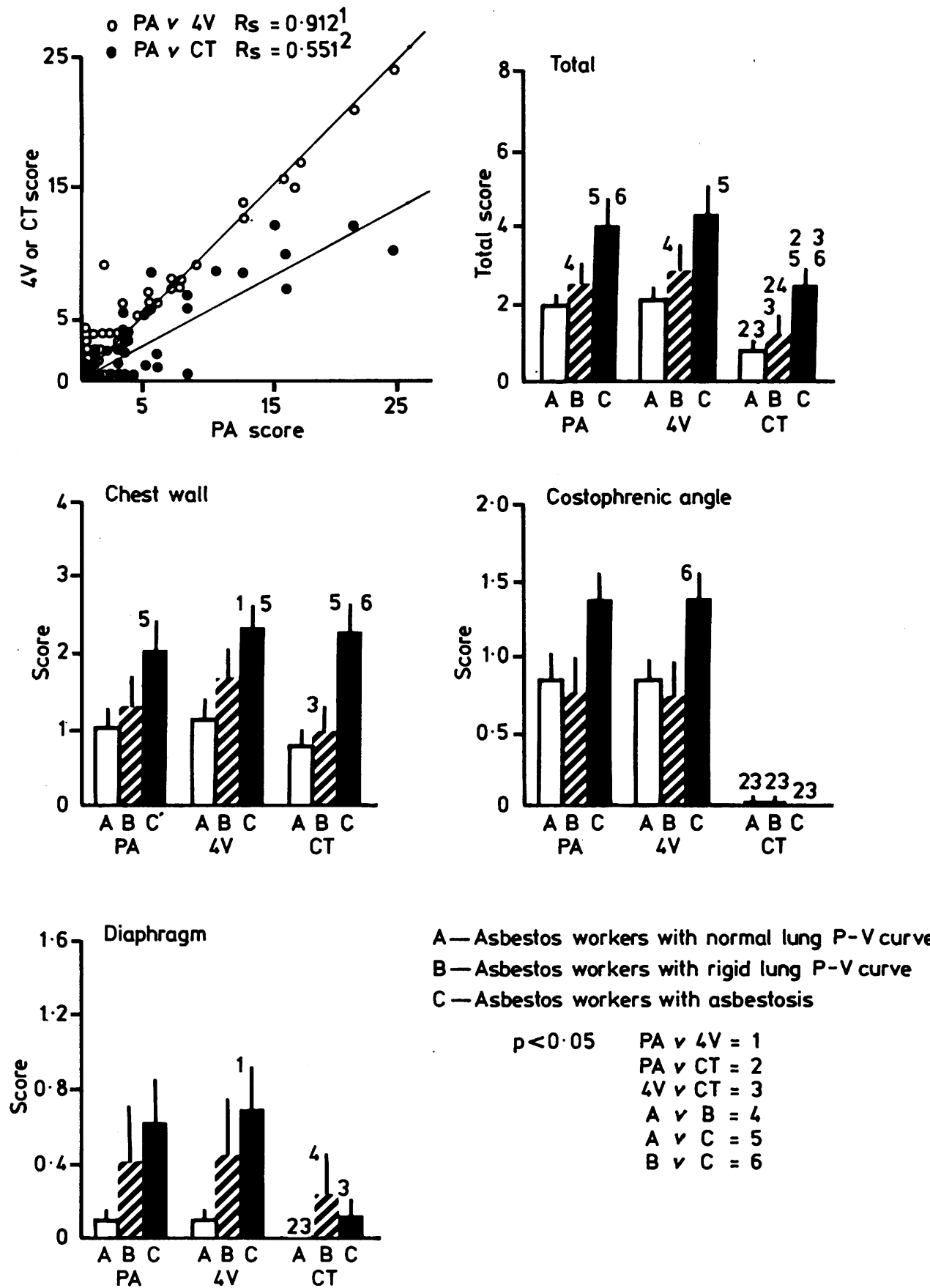

C-Asbestos workers with asbestosis

$$
\begin{array}{r}
P<0.05 \quad P A \vee L V=1 \\
P A \vee C T=2 \\
4 V \vee C T=3 \\
A \vee B=4 \\
A \vee C=5 \\
B \vee C=6
\end{array}
$$

Fig 4 Total and regional scores of profusion of pleural thickening by the three methods. Abbreviations as in fig 2 . 

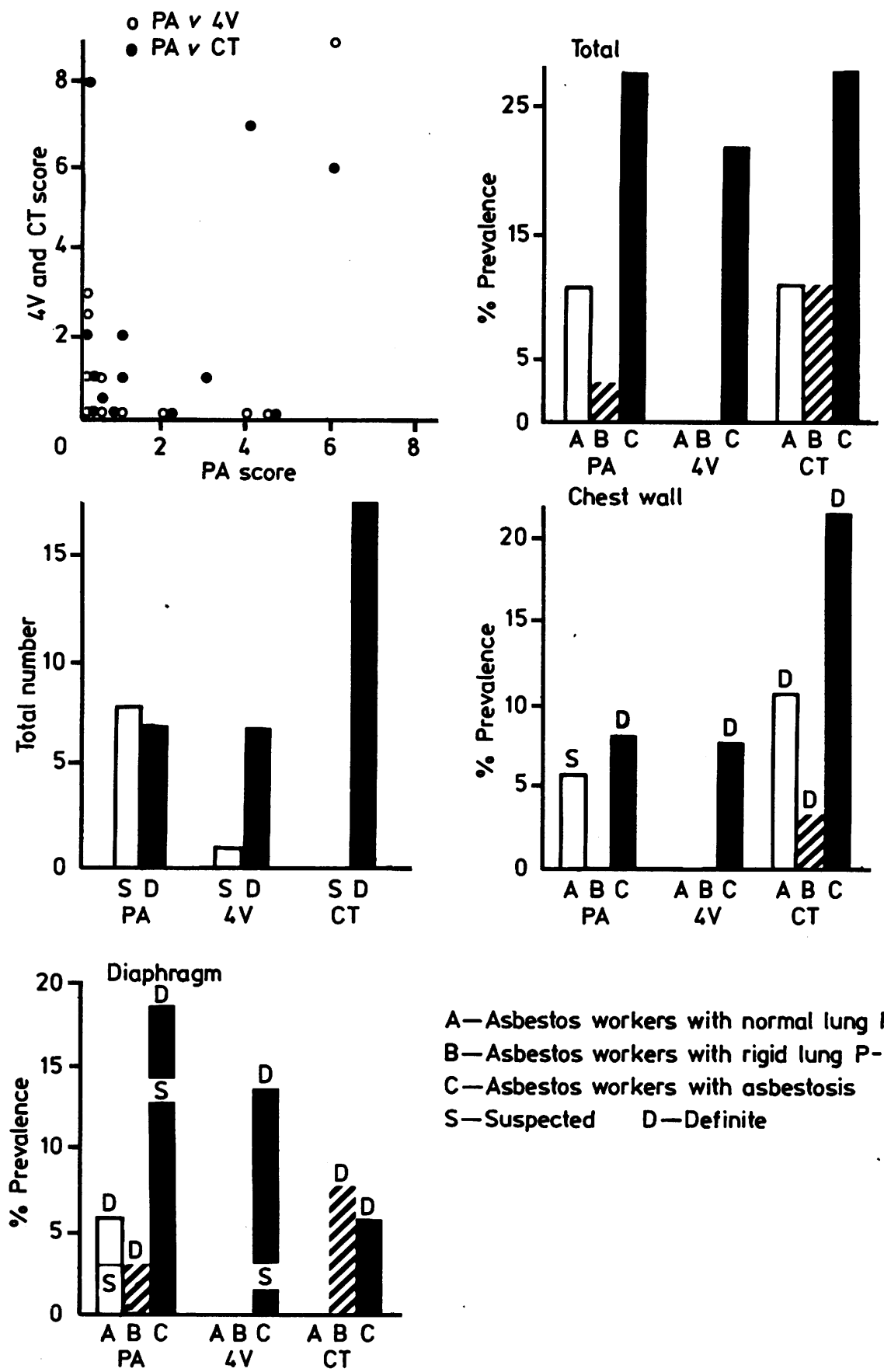

A-Asbestos workers with normal lung P-V curve

$B-$ Asbestos workers with rigid lung $P-V$ curve

C-Asbestos workers with asbestosis

S-Suspected D-Definite

Fig 5 Total and regional scores of profusion of pleural calcifications by the three methods. Scores at costophrenic angles are not reported as only three calcifications were identified here. 

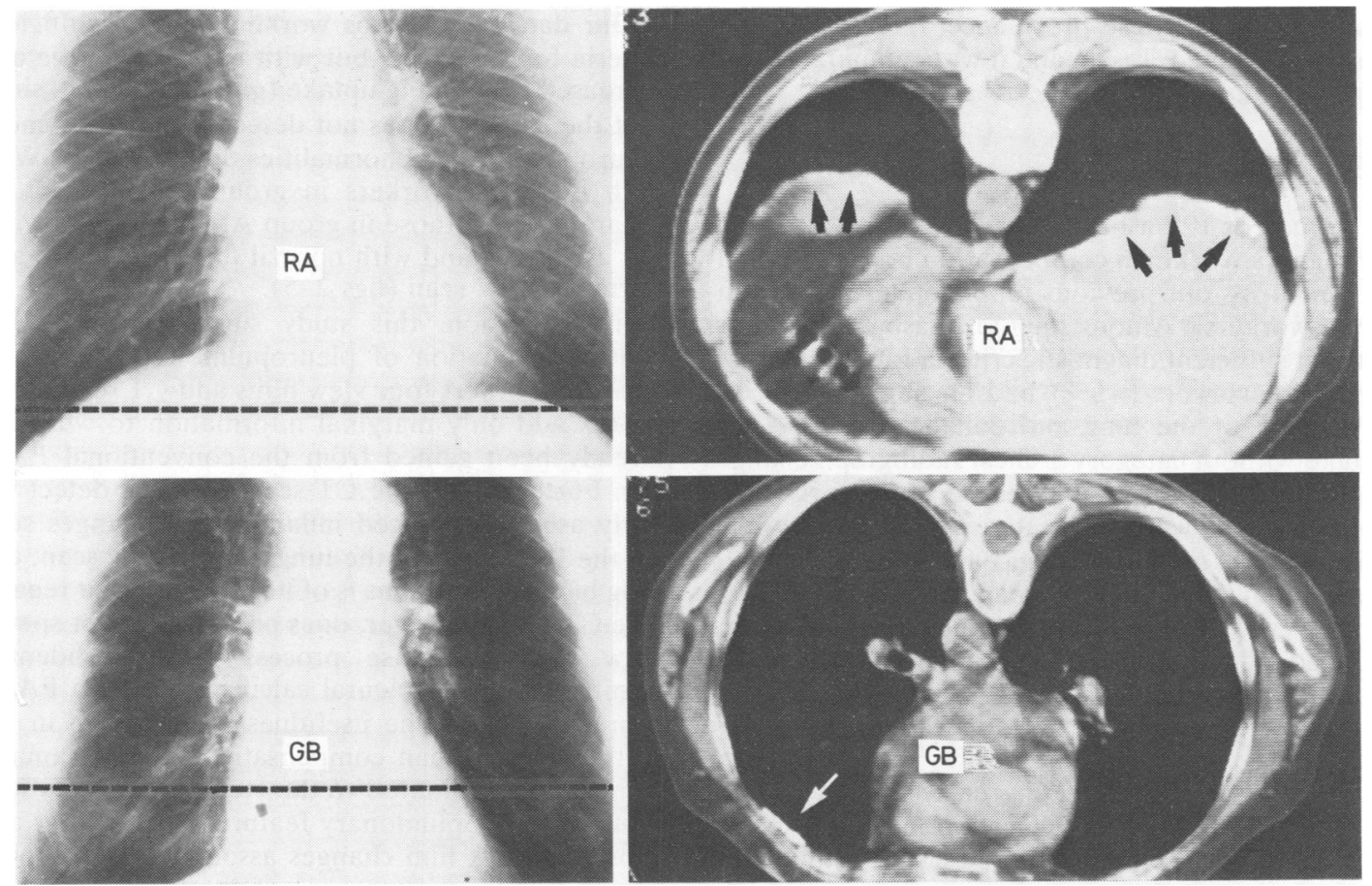

Fig 6 Posteroanterior chest radiograph and CT scan of thorax of two asbestos workers showing calcified pleural plaques on the diaphragm and anterior chest wall by CT scan. These could not be detected on PA or four view films. Dashed lines on PA views indicate approximate level of CT scan. Arrows on CT scan indicate classified pleural plaques.

PROFUSION OF PARENCHYMAL OPACITIES

As may be seen in fig 3 , a similar assessment of parenchymal disease was obtained from the PA, four view, and CT scan methods but, again, the individual variations were wider for the CT scan. As expected, profusion scores were higher in the middle and lower lung fields. Again the group B scores (total and for each lung field) did not differ between methods. In 10 of the $53(19 \%)$ workers with the disease (group C) the lung process was not recognised by the CT scan.

\section{PLEURAL PLAOUES}

The highest overall score for pleural thickening without associated calcification was obtained by four view films, followed by PA film and CT scan (fig 4). This was due largely to the slightly lower scores of the PA versus four view method at all sites and the lower scores of the CT scan at the costophrenic angles and diaphragms. In group B the scores for pleural plaques were the highest on four view films, followed by PA and CT scan. When comparing PA and four view films, the scores were identical in $73 \%$, higher for PA in 7\%, and higher for four view films in 19\%. The CT scan scores were identical with PA in $31 \%$, higher for CT scan in $13 \%$ (largely because of higher scores on lateral pleural sites), and lower for the CT scan in $56 \%$ (because of lower scores at diaphragm and costophrenic angle sites).

\section{PLEURAL CALCIFICATIONS}

Figure 5 shows the data on calcified pleural plaques. In patients with established asbestosis (group C) the prevalence rate was in the $20-30 \%$ range by all three methods. Large discrepancies between methods could be seen in the other groups, and no significant correlation between the three methods was found in the total score of pleural calcifications. Whereas nine pleural calcifications were suspected on PA film alone, only two were confirmed by one other method. As expected, the prevalence rate of definite pleural calcifications was highest in group $C$. Of the 27 calcified pleural plaques considered definite, 14 were seen only on the CT scan (fig 6). In 
group $B$ the highest prevalence rate $(10 \%)$ was observed on the CT scan and it was comparable with that of group $\mathbf{A}$.

\section{Discussion}

This study of 127 asbestos workers evaluated in the setting of a workman compensation board examination confirms our previous report on a smaller sample of workers. ${ }^{9}$ Among long term asbestos workers without sufficient diagnostic criteria for asbestosis, a subset of workers $(41 \%)$ had an abnormally rigid $\mathrm{P}-\mathrm{V}$ curve of the lung and enhanced $\mathrm{Ga} 67$ lung uptake without category 1 chest radiograph changes or audible rales (fig 1). Because these early functional changes were associated with histopathological evidence of macrophagic and monocytic peribronchiolar alveolitis in man and in the sheep model, ${ }^{9}$ we suggest that they detect early asbestos induced inflammatory changes in the lung that could lead to pulmonary fibrosis.

As the CT scan was reported to be more sensitive than the conventional chest $x$ ray ${ }^{5}$ or pulmonary function tests ${ }^{17}$ for detecting early interstitial lung disease, we obtained a CT scan for these asbestos workers. The potential of the CT scan for the detection of pleuropulmonary disease was assessed by grading the profusion of pleural and pulmonary disease in a setting independent of the compensation board examination and without access to the information gathered for the board examination. The results were then compared with the grading from the PA film alone and from four view films also obtained independently.

Our analysis of the total scores of the pleuropulmonary changes (fig 2) and profusion of parenchymal opacities (fig 3) shows that the three methods can detect about the same total amount of abnormalities in each subset of workers, which is at variance with previous clinical reports. ${ }^{56}$ Pleural plaques were scored slightly higher on the four view films than on the PA film, in agreement with a previous report comparing these methods, ${ }^{18}$ but pleural plaques were scored significantly lower on the CT scan, mostly because of the lower yields at the costophrenic angles and diaphragms. The largest discrepancies between the three methods were observed in the evaluation of pleural calcifications. On PA films, calcified pleural plaques were often suspected but could be confirmed by one of the other methods in only two of nine cases. Of the 27 definite pleural calcifications detected in our 127 asbestos workers, however, 14 were detected only by CT scan (fig 6) and all those detected by the PA and four view films were also observed on the CT scan.
Our data on asbestos workers without sufficient criteria for asbestosis but with rigid $\mathrm{P}-\mathrm{V}$ curve and increased Ga 67 lung uptake (group B) (fig 1), show that the CT scan does not detect significantly more pleuropulmonary abnormalities than PA films. With both methods, workers in group $B$ could not be separated from those in group A, the workers without asbestosis and with normal lung $\mathrm{P}-\mathrm{V}$ curve and normal Ga 67 scan (figs 2-5).

In conclusion, this study suggests that in the routine evaluation of pleuropulmonary disease in asbestos workers four view films and CT scan of the thorax add only marginal information to what has already been gained from the conventional PA $x$ ray. Furthermore, the CT scan does not detect the early asbestos induced inflammatory changes seen on the P-V curve of the lung, Ga 67 lung scan, and lung biopsies, and thus is of little help in that regard. The CT scan, however, does provide a better spatial view of the disease process and can identify significantly more pleural calcifications than PA or four view films. The usefulness of CT scan in the setting of workman compensation board examination should be limited to the study of workers with unusual pleuropulmonary features on PA films and those with PA film changes associated with low or uncertain asbestos exposure where the identification of calcified pleural plaques would support the clinical diagnosis of asbestosis.

This study has been supported by IRSST, Québec.

\section{References}

' Kreel L. Computed tomography of the lung and pleura. Semin Roentgenol 1978;13:213-25.

2 Jost RG, Sagel SS, Stanley RJ, Levitt RG. Computed tomography of the thorax. Radiology 1978;126:125-36.

${ }^{3}$ Pugatch RD, Faling LJ. Computed tomography of the thorax: a status report. Chest 1981;80:618-26.

${ }^{4}$ Brown LR, Muhm JR. Computed tomography of the thorax. Current perspectives. Chest 1983;83:806-13.

${ }^{5} \mathrm{Kreel}$ L. Computer tomography in the evaluation of pulmonary asbestosis: preliminary experiences with the EMI general purpose scanner. Acta Radiol Diag 1976; 17:405-12.

- Katz D, Kreel L. Computed tomography in pulmonary asbestosis. Clin Radiol 1979;30:207-13.

7 Murphy RLH, Gaensler EA, Ferris BG, Fitzgerald M, Solliday N, Morrisey W. Diagnosis of "asbestosis." Observations from a longitudinal survey of shipyard pipe coverers. Am J Med 1978;65:488-98.

${ }^{8}$ Helsing KJ, Comstock GW, Speizer FE, et al. Comparison of three standardized questionnaires on respiratory symptoms. Am Rev Respir Dis 1979;120:1221-31.

${ }^{9}$ Bégin R, Cantin A, Drapeau G, et al. Pulmonary uptake of Gallium-67 in asbestos exposed human and sheep. Am Rev Respir Dis 1983;127:623-30.

${ }^{10}$ ILO/UC International Classification of radiographs of pneumoconiosis 1980 . No 22 revised. Occupational Safety and Health Series. Geneva: International Labour Office, 1980. 
" Bates DV, Macklem PT, Christie RV. The normal lung: physiology and methods of study. In: Respiratory function in disease. Philadelphia: WB Saunders, 1971;11-95 and 276-80.

12 Bégin R, Renzetti AD, Bigler AH, Watanabe S. Flow and age dependence of airway closure and dynamic compliance. J Appl Physiol 1975;38:199-207.

${ }_{13}$ Bisson G, Drapeau G, Lamoureux G, Cantin A, Bégin R. Computer based quantitative analysis of Gallium-67 uptake in normal and diseased lungs. Chest 1983:83:513-7.

${ }_{14}$ Task force on occupational respiratory disease. Health and Welfare Canada 1979;35-48. is Snedecor GW, Cochran WC. Statistical methods. Ames Iowa: Iowa State University Press, 1967.

${ }^{10}$ Siegel S. Non-parametric statistics. New-York: McGraw-Hill, 1956:195-240.

${ }^{17}$ Fahey PJ, Utell MJ, Wandtke JC, et al. Early detection of bleomycin induced pulmonary fibrosis. Am Rev Respir Dis 1982; 126: 126-30.

${ }^{18}$ Reger RB, Ames RG, Merchant JA, et al. The detection of thoracic abnormalities using posterior-anterior (PA) vs PA and oblique roentgenograms. Chest 1982;81:290-5. 